\title{
Atypical femoral fractures related to bisphosphonate therapy
}

\author{
Tarun Pankaj Jain, Murray Thorn \\ Queensland X ray, 76 Willetts Road, Mackay - 4740, 11985 Logan Road, Upper Mount Gravatt - 4122, Queensland, Australia
}

Correspondence: Dr. Tarun Pankaj Jain, 18 Barron Street, Deakin - 2600, Australia. E-mail: drtjain@yahoo.com

\begin{abstract}
Bisphosphonates (BP) are a commonly prescribed class of drugs for the prevention of osteoporosis-related fractures. Paradoxically, however, they have recently been linked to atypical fractures in the shaft of the femur. Since many physicians including radiologists, are not aware of this entity, the incidence is likely underreported. These fractures usually occur in the sub-trochanteric region of the femur in the setting of low-energy trauma. It starts as a fracture line involving the lateral cortex and then progresses medially to give rise to a complete fracture. The fracture line is usually transverse, and there is a medial spike associated with a complete fracture. These fractures can be bilateral. Awareness of these atypical fractures and their radiological appearance should enable their early and accurate detection and thus lead to specific treatment.
\end{abstract}

Key words: Bisphosphonates; femoral fractures; hip fractures

\section{Introduction}

Bisphosphonates (BP) are a commonly prescribed class of drugs for the prevention of osteoporosis-related fractures. ${ }^{[1]}$ However, paradoxically, they have been recently linked to fractures in the shaft of the femur. ${ }^{[2]}$ These fractures have been termed 'atypical' fractures. There are scant reports in radiology literature on these atypical fractures. ${ }^{[3-8]}$ In fact, since many physicians including radiologists are not conscious of this entity, these fractures are often not recognized as a specific condition and thus may be treated like any other fracture. ${ }^{[2]}$

These fractures have a characteristic location and appearance on radiographs. ${ }^{[1-3]}$ In this article, we describe the radiological features of these fractures as seen in four patients and present a brief review of the literature. The findings in these four cases cover all the different typical features reported.

\begin{tabular}{|l|l|}
\hline \multicolumn{2}{|c|}{ Access this article online } \\
\hline Quick Response Code: & Website: \\
\hline & www.ijri.org \\
\hline & \\
& DOI: \\
\hline
\end{tabular}

\section{Case Reports}

Patient 1

A74-year-old woman presented with pain around her left hip for one month. She was on BP (alendronate) for four years. The radiographs of her hip and upper femur [Figure 1A] were interpreted as normal. She presented again one month later with increase in the pain. The radiographs now showed an incomplete transverse fracture in the sub-trochanteric shaft of the femur, involving the lateral half of the shaft [Figure 1B]. She was managed with fixation of the fracture. A retrospective review of the earlier radiograph showed subtle thickening and beaking of the lateral cortex of the femur [Figure 1C], the site of subsequent development of the fracture. A follow-up radiograph after 8 months showed incomplete healing of the fracture.

\section{Patient 2}

A 77-year-old patient presented with acute pain in her right thigh. She had had a sudden fall while walking with the aid of a walker. The radiographs of the femur showed a complete, non-comminuted, short oblique fracture in the proximal shaft of the femur [Figure 2A]. A sharp spike was present in the medial cortex. She was on BP (alendronate) for seven years. The fracture was treated with internal fixation.

Five months later she again had a fall while trying to get up from a chair and presented with acute pain in her left 
thigh. The radiographs showed a fracture in the proximal shaft of the left femur [Figure 2B]. It had a similar location and configuration as the earlier fracture in the right femur. This fracture was also fixed internally. Post-reduction and fixation radiographs showed beaking of the lateral cortex at the fracture site [Figure $2 \mathrm{C}$ ].

\section{Patient 3}

A 71-year-old woman presented with pain for four months around her left hip. She was on BP (alendronate) for 10 years. The radiograph showed mild thickening and beaking of the lateral cortex of the upper shaft of femur, below the level of the trochanter [Figure 3]. She was managed with withdrawal of BP and limitation of weight bearing to prevent development of a fracture. Her symptoms improved over a period of 3-4 months. There was no subsequent development of fracture and she was asymptomatic at follow up after one year.

\section{Patient 4}

A 75-year-old woman presented with pain in her left hip for three weeks. She had a history of previous fixation of an intertrochanteric fracture of the left femur with a dynamic hip screw (DHS) seven years ago. She was on $\mathrm{BP}$ (risedronate) for $5 \frac{1}{2}$ years. A plain radiograph of the left hip was interpreted as normal [Figure 4A]. In view of her symptoms and previous DHS fixation, a nuclear bone scan was performed. This revealed increased uptake in the lateral cortex of the upper femoral shaft, below the level of the trochanters, consistent with an insufficiency fracture [Figure 4B]. Due to the presence of the DHS screw, her upper femur was considered to be protected against a stress fracture. She was managed conservatively with limitation of weight bearing. Her symptoms improved over a period of two months, and she continues to be asymptomatic in this region after one year of follow up.

\section{Discussion}

Bisphosphonates are widely used for the treatment of osteoporosis. The occurrence of atypical femoral fractures in patients taking BP was first reported by Odvina, et al..$^{\left[{ }^{9]}\right.}$ Recently, a multidisciplinary task force of the American Society for Bone and Mineral Research (ASBMR) reexamined the key questions by reviewing the published reports of atypical femoral fractures and tried to get an insight into the pathogenesis and treatment of these fractures. ${ }^{[2]}$

According to this task force's criteria for the diagnosis of 'atypical' fractures, femoral fractures with sub-trochanteric extension, pathological fractures associated with tumors, and peri-prosthetic fractures are to be specifically excluded. Atypical fractures have to satisfy all the major criteria, i.e., location from distal to lesser trochanter to just proximal to the supracondylar flare; no history of trauma or only minimal trauma (fall from standing height or
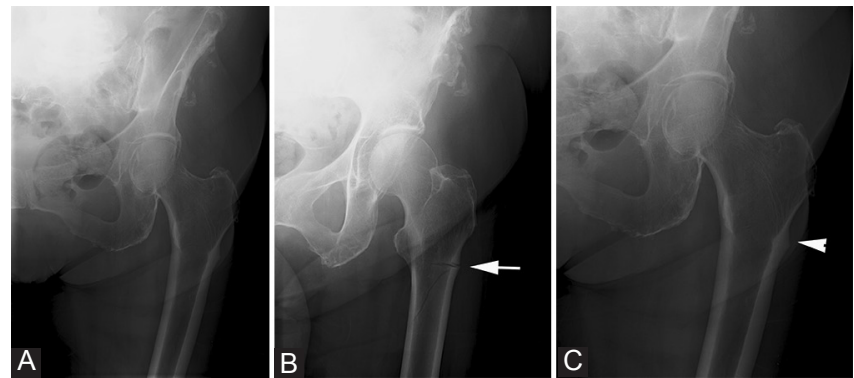

Figure $1(A-C)$ : Patient 1: The initial frontal radiograph of the left hip (A) was reported as normal. The patient presented again after 1 month, when a frontal radiograph (B) showed an incomplete fracture (arrow) involving the lateral aspect of the proximal femoral shaft, below the level of the greater trochanter. A review of the initial radiograph $(C)$ showed subtle breaking of the lateral cortex (arrowhead)

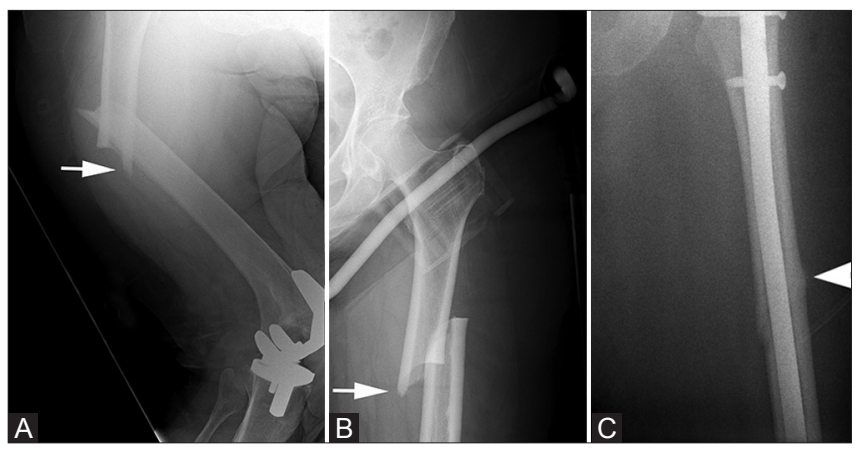

Figure 2 (A-C): Patient 2: Radiograph of the right femur (A) shows the typical complete fracture of the proximal femur (arrow). Anteroposterior radiograph of the left hip (B) of the same patient 5 months later shows a similar fracture (arrow). Post-operative radiograph after surgical fixation $(C)$ shows beaking and thickening of the lateral cortex at site of the original fracture (arrowhead)
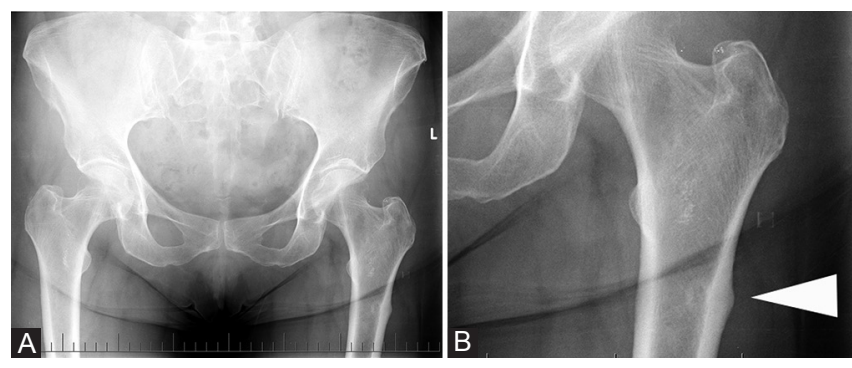

Figure 3 (A, B): Patient 3: Anteroposterior radiograph $(A)$ and its zoomed image (B) show the typical beaking (arrowhead) of the lateral cortex of the femur, which is seen with atypical fractures related to BP therapy

less); transverse or short oblique configuration; complete fractures may be associated with a medial spike, while incomplete fractures involve the lateral cortex only. ${ }^{[2]}$

The fracture begins as a small beak-like localized cortical thickening of the lateral cortex. Then, an incomplete lucent lateral stress fracture appears, which progressively extends to involve both the medial and the lateral cortices. ${ }^{[2,3]}$

In patient 1 , the first radiograph showed a beak-like cortical thickening [Figure 1] that was missed on initial 

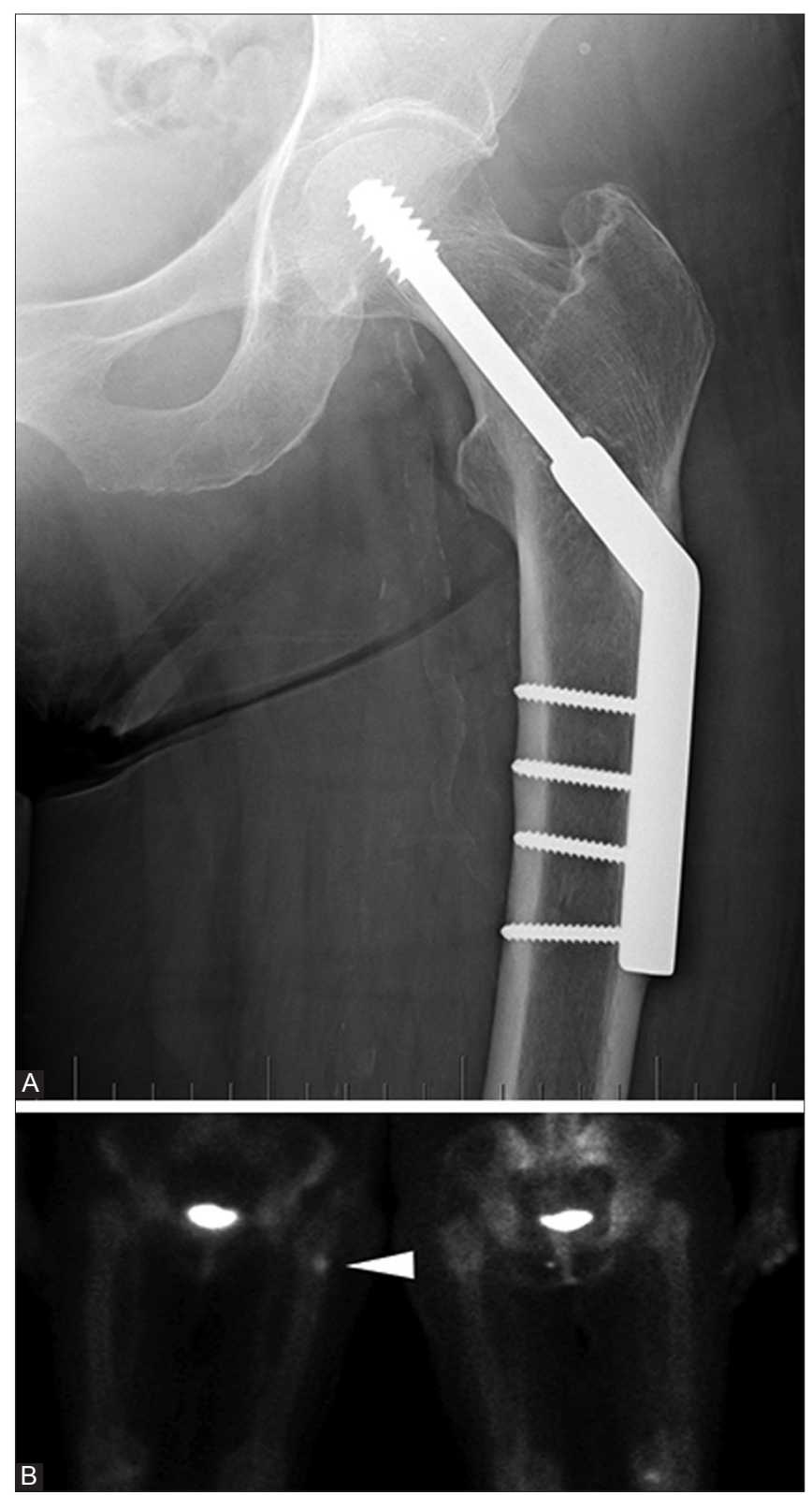

Figure 4 (A, B): Patient 4: Anteroposterior radiograph (A) does not show any fracture. Nuclear bone scan (B) shows uptake in the lateral cortex, below the level of the trochanter (arrowhead)

assessment. This patient presented again after one month with an incomplete fracture involving the lateral cortex only [Figure 2]. Similar lateral cortical thickening was also seen in the radiograph of patient 3 [Figure 3B].

Patients 1 and 3 also had pain around the affected hip (for one month and four months, respectively). This symptom can be misdiagnosed as being due to degenerative disease of the lumbar spine and sacroiliac joints. The task force appointed by the ASBMR reviewed 310 cases and found that this prodromal pain can be present in up to $70 \%$ of patients. ${ }^{[2]}$ This characteristic pain associated with such atypical fractures was first reported by Goh, et al., who reported that it can be present for a duration of 2-6 months before the actual fracture. ${ }^{[10]}$ Thus, if a patient on BP therapy presents with pain around the hip, the shaft of the femur should be a review area on radiographs.

Patient 2 had sequential bilateral fractures. This is seen in up to $28 \%$ of patients. ${ }^{[2]}$ Both the fractures in patient 2 showed the typical spike of the medial cortex [Figure 2A, B] which can be associated with atypical fractures when they are complete and involve both the lateral and the medial cortices. ${ }^{[2,3]}$ Both the fractures were treated with open reduction and internal fixation with an intramedullary nail. Many times, the postoperative radiograph after fixation shows the thickening and beaking of the lateral cortex, representing the original fracture [Figure 2C]. ${ }^{[2,3]}$ In view of the high incidence of bilateral fractures, if a patient presents with a unilateral fracture, it is imperative to assess the radiograph of the opposite hip and femur to rule out subtle changes on the other side. ${ }^{[3]}$ When our patient presented with the fracture in the right femur she gave the history of a fall while walking with the aid of a walker. When she presented next with a fracture in the left femur, she said that she had fallen when trying to get up from a chair. This is consistent with the typical presentation of low-energy impact fractures, which usually occur with daily activities, without major falls or trauma. ${ }^{[2,3]}$

Patient 4 had had an intertrochanteric fracture seven years ago that had been internally fixed with a dynamic hip screw (DHS). Her radiograph was unremarkable. However, a nuclear bone scan [Figure 3] showed focal increase in uptake in the lateral cortex of the upper femur in the sub-trochanteric location, the typical site for atypical fractures. Due to the presence of the DHS screw, her upper femur was protected against a stress fracture. This suggests that the abnormal uptake was due to an insufficiency fracture related to BP intake. Similar findings have been described earlier. ${ }^{[2,4]}$

All of our patients were taking BPs for more than five years. It is prolonged intake of BPs - usually for more than three years - that has been linked to atypical fractures. ${ }^{[2]}$ In a recent study on 70 patients who had low-energy femoral fractures, 10 patients with features of atypical fractures reported a mean 6.9 years of intake of BP (alendronate) compared to a mean of 2.5 years of intake of BP in the 6 patients not showing features of atypical fracture. ${ }^{[1]}$

According to a recent study by Schilcher, et al., the risk of insufficiency fractures was 47 times higher in patients taking BPs. ${ }^{[11]}$ This risk increased with the duration of drug use and reduced by $70 \%$ per year after drug withdrawal. However, despite the increased risk, the absolute risk remains small and BPs still have a high risk-benefit ratio for the prevention of osteoporosis-related fractures. ${ }^{[2,11]}$ Still, given the widespread use of BP drugs, even a small fraction of patients at risk of fracture is of clinical significance. In 
a recent prospective study of 100 asymptomatic patients taking BPs for more than three years, there was a $2 \%$ frequency of incomplete atypical femoral fractures. ${ }^{[5]}$

If a patient on BP therapy presents with groin or thigh pain and the radiograph is normal, then a nuclear bone scan or MRI should be considered. Once a fracture is demonstrated, surgical treatment is recommended. ${ }^{[2]}$ The differential diagnosis of fractures in the shaft of femur includes stress fracture, pseudo fractures or Looser zones, and pathologic fracture related to underlying bone tumors. ${ }^{[3]}$ The stress fractures and Looser zones usually involve the medial cortex while the BP associated fractures initially involve the lateral cortex. Pathological fractures usually show the associated underlying lucent lesion and poorly defined margins. ${ }^{[3]}$

\section{Conclusion}

The typical radiographic pattern of fractures in the shaft of femur in the setting of low-energy trauma is characteristic of insufficiency fractures related to BP intake ${ }^{[3]}$ In view of the widespread use of BPs, it is necessary for the radiologist to carefully evaluate the shaft of femur on radiographs in any patient with hip pain, especially in the elderly age-group. If a suspicious fracture pattern is encountered, then historical information should be sought and the case should be discussed with the referring physician.

\section{References}

1. Neviaser AS, Lane JM, Lenart BA, Edobor-Osula F, Lorich DG. Low-energy femoral shaft fractures associated with alendronate use. J Orthop Trauma 2008;22:346-50.

2. Shane E, Burr D, Ebeling PR, Abrahamsen B, Adler RA, Brown TD, et al. Atypical subtrochanteric and diaphyseal femoral fractures: report of a task force of the American Society for bone and mineral research. J Bone Miner Res 2010;25:2267-94.

3. Porrino JA, Kohl CA, Taljanovic M, Rogers LF. Diagnosis of proximal femoral insufficiency fractures in patients receiving bisphosphonate therapy. AJR Am J Roentgenol 2010;194:1061-4.

4. Bush LA, Chew FS. Subtrochanteric femoral insufficiency fracture following bisphosphonate therapy for osseous metastases. Radiol Case Rep 2008;3:232.

5. La Rocca Vieira R, Rosenberg ZS, Allison MB, Im SA, Babb J, Peck V. Frequency of incomplete atypical fractures in asymptomatic patients on long term bisphosphonate therapy. AJR Am J Roentgenol 2012;198:1144-51.

6. Kilcoyne A, Heffernan EJ. Atypical proximal femoral fractures in patients with Paget disease receiving bisphosphonate therapy. AJR Am J Roentgenol 2011;197:W196-7.

7. Png MA, Koh JS, Goh SK, Fook-Chong S, Howe TS. Bisphosphonate-related femoral periosteal stress reactions: Scoring system based on radiographic and MRI findings. Am J Roentgenol 2012;198:869-77.

8. Rosenberg ZS, La Rocca Vieira R, Chan SS, Babb J, Akyol Y, Rybak LD, et al. Bisphosphonte-related complete atypical subtrochantric femoral fractures: Diagnostic utility of radiography. AJR Am J Roentgenol 2011;197:954-60.

9. Odvina CV, Zerwekh JE, Rao DS, Maalouf N, Gottschalk FA, Pak CY. Severely suppressed bone turnover: A potential complication of alendronate therapy. J Clin Endocrinol Metab 2005;90:1294-301.

10. Goh SK, Yang KY, Koh JS, Wong MK, Chua SY, Chua DT, et al. Subtrochanteric insufficiency fractures in patients on alendronate therapy: A caution. J Bone Joint Surg Br 2007;89:349-53.

11. Schilcher J, Michaelsson K, Asperberg P. Bisphosphonate use and atypical fractures of the femoral shaft. N Engl J Med 2011;364:1728-37.

Cite this article as: Jain TP, Thorn M. Atypical femoral fractures related to bisphosphonate therapy. Indian J Radiol Imaging 2012;22:178-81.

Source of Support: Nil, Conflict of Interest: None declared.

\section{Author Help: Online submission of the manuscripts}

Articles can be submitted online from http://www.journalonweb.com. For online submission, the articles should be prepared in two files (first page file and article file). Images should be submitted separately.

1) First Page File:

Prepare the title page, covering letter, acknowledgement etc. using a word processor program. All information related to your identity should be included here. Use text/rtt/doc/pdf files. Do not zip the files.

2) Article File:

The main text of the article, beginning with the Abstract to References (including tables) should be in this file. Do not include any information (such as acknowledgement, your names in page headers etc.) in this file. Use text/rtt/doc/pdf files. Do not zip the files. Limit the file size to $1024 \mathrm{~kb}$. Do not incorporate images in the file. If file size is large, graphs can be submitted separately as images, without their being incorporated in the article file. This will reduce the size of the file.

3) Images:

Submit good quality color images. Each image should be less than $\mathbf{4 0 9 6} \mathbf{~ k b ~ ( 4 ~ M B ) ~ i n ~ s i z e . ~ T h e ~ s i z e ~ o f ~ t h e ~ i m a g e ~ c a n ~ b e ~ r e d u c e d ~ b y ~ d e c r e a s - ~}$ ing the actual height and width of the images (keep up to about 6 inches and up to about $1800 \times 1200$ pixels). JPEG is the most suitable file format. The image quality should be good enough to judge the scientific value of the image. For the purpose of printing, always retain a good quality, high resolution image. This high resolution image should be sent to the editorial office at the time of sending a revised article.

4) Legends:

Legends for the figures/images should be included at the end of the article file. 